\title{
Interaction of Cardiopulmonary and Carotid Baroreflex Control of Vascular Resistance in Humans
}

\author{
Ronald G. Victor and Allyn L. Mark \\ Cardiovascular Center and Department of Internal Medicine, University of Iowa College of Medicine and Veterans Administration \\ Medical Center, Iowa City, Iowa 52242; Cardiology Division, Department of Internal Medicine, \\ Duke University Medical Center, Durham, North Carolina 27710
}

\section{Abstract}

Previous studies in experimental animals indicate an important inhibitory interaction between cardiopulmonary and arterial baroreflexes. In the dog, for example, cardiopulmonary vagal afferents modulate carotid baroreflex control of vascular resistance. On the other hand, previous studies in human subjects have not produced convincing evidence of a specific interaction between these baroreceptor reflexes.

The purpose of this study was to determine whether unloading of cardiopulmonary baroreceptors in humans with nonhypotensive lower body negative pressure selectively augments the reflex vasoconstrictor responses to simulated carotid hypotension produced by neck pressure. In nine healthy subjects, we measured forearm vascular responses with plethysmography during lower body negative pressure alone (cardiopulmonary baroreflex), during neck pressure alone (carotid baroreflex), and during concomitant lower body negative pressure and neck pressure (baroreflex interaction). Lower body negative pressure produced a greater than twofold augmentation of the forearm vasoconstrictor response to neck pressure. This increase in resistance was significantly greater $(P<0.05)$ than the algebraic sum of the increase in resistance from lower body negative pressure alone plus that from neck pressure alone. In contrast, lower body negative pressure did not potentiate the forearm vasoconstrictor responses either to intra-arterial norepinephrine or to the cold pressor test. Thus, the potentiation of the vasoconstrictor response to neck pressure by lower body negative pressure cannot be explained by augmented reactivity to the neurotransmitter or to a nonspecific augmentation of responses to all reflex vasoconstrictor stimuli.

In conclusion, nonhypotensive lower body negative pressure selectively augments carotid baroreflex control of forearm vascular resistance. These experiments demonstrate a specific inhibitory cardiopulmonary-carotid baroreflex interaction in humans.

A preliminary report of this work was presented at the 56th Scientific Session of the American Heart Association in Anaheim, CA on 16 November 1983, and has been published as an abstract (1983. Circulation. 68:III-248).

Address reprint requests to Dr. Victor, Cardiovascular Division, Department of Internal Medicine, University of lowa Hospitals, Iowa City, IA 52242.

Received for publication 30 December 1983 and in revised form 3 July 1985

J. Clin. Invest.

(c) The American Society for Clinical Investigation, Inc.

$0021-9738 / 85 / 10 / 1592 / 07 \quad \$ 1.00$

Volume 76, October 1985, 1592-1598

\section{Introduction}

Hypotension and hypovolemia often occur together in the clinical setting, so the arterial and cardiopulmonary baroreceptors are affected simultaneously (1). In most experimental studies of arterial and cardiopulmonary baroreflexes in humans, however, the reflexes have been activated individually, and the possibility of reflex interaction has received little attention (2). In contrast, an important interaction between high and low pressure baroreceptor reflexes has been demonstrated repeatedly in experimental animals (3-12). In the dog, for example, interruption of cardiopulmonary vagal afferents augments vasoconstrictor responses to carotid hypotension (12).

Baroreflex interactions are obviously more difficult to study in human subjects than in experimental animals. In previous human studies of this reflex interaction, cardiopulmonary baroreflexes have been perturbed with lower body negative pressure (LBNP) $^{1}$ and carotid baroreflexes with neck suction. Using these methods, earlier experiments in this laboratory demonstrated that physiologic variations in central venous pressure do not alter carotid baroreflex control of heart rate in humans (13). Previous studies have also examined vascular responses during combined application of LBNP at $-40 \mathrm{mmHg}$ and neck suction (14-16). Because LBNP at $-40 \mathrm{mmHg}$ itself produces significant decreases in arterial pressure and therefore unloads both high and low pressure baroreceptors, these studies do not permit definitive conclusions concerning a possible interaction between cardiopulmonary and carotid baroreflex control of vascular resistance.

Therefore, the purpose of this study was to determine $(a)$ whether selective unloading of cardiopulmonary receptors with nonhypotensive LBNP augments carotid baroreflex control of vascular resistance in humans, and $(b)$ whether this effect of LBNP represents a specific inhibitory interaction of cardiopulmonary and carotid baroreflexes rather than a nonspecific generalized augmentation of vascular reactivity or reflex responsiveness.

There are several distinctive features of this study compared to the previous human studies of cardiopulmonary-carotid baroreflex interaction. First, we focused on forearm vascular resistance. Because autonomic responses can be highly differentiated, important regional changes in vasomotor tone may not be detected if only systemic arterial pressure and total peripheral resistance are studied $(2,17,18)$. Second, we used neck pressure rather than neck suction to trigger carotid baroreflex responses. The rationale for studying the interaction during decreases in carotid sinus transmural pressure (neck pressure) was based on previous animal experiments in which cardiopulmo-

1. Abbreviation used in this paper: LBNP, lower body negative pressure. 
nary vagal afferents modulate carotid baroreflex control of vascular resistance during carotid hypotension but not during carotid hypertension (12). Third, we used LBNP at $-10 \mathrm{mmHg}$ rather than at $-40 \mathrm{mmHg}$ in triggering cardiopulmonary baroreflex responses. Because $\mathrm{LBNP}$ at $-10 \mathrm{mmHg}$ decreases central venous pressure but does not decrease mean arterial pressure, pulse pressure, or arterial $\mathrm{d} p / \mathrm{d} t(19-22)$, the assumption is that LBNP at $-10 \mathrm{mmHg}$ produces selective unloading of cardiopulmonary vagal afferents without altering the mechanical determinants of carotid (or aortic) baroreceptor discharge. Fourth, to determine the specificity of the effect of LBNP on forearm vascular responses to neck pressure, we also studied the effects of LBNP on vasoconstrictor responses to the cold pressor test and to intra-arterial norepinephrine.

\section{Methods}

Subjects. 22 healthy male volunteers, ages $18-29 \mathrm{yr}$, were studied without sedation in the supine, postabsorptive state. All subjects were free of cardiovascular disease based on a medical history and physical examination and were not receiving any medication at the time of the study. Each subject gave written informed consent. The study protocol was approved by the Human Subjects Review Committee at the University of lowa.

Procedures. Forearm blood flow was measured by venous occlusion plethysmography, using a mercury-in-silastic Whitney strain gauge (23). The strain gauge was placed $\sim 5 \mathrm{~cm}$ distal to the antecubital fossa. The arm was elevated and supported so that the proximal forearm was $\sim 10$ $\mathrm{cm}$ above the anterior chest wall. Circulation to the hand was arrested by inflating a cuff around the wrist to $180 \mathrm{mmHg}$ during determinations of forearm blood flow. The pressure of the venous congesting cuff in the upper arm was $40 \mathrm{mmHg}$. Forearm blood flow was measured at 15 -s intervals.

Arterial pressure was measured in the arm either by sphygmomanometry, with one observer performing all measurements, or by an indwelling arterial cannula (No. 6 French) which was inserted under local anesthesia (1\% xylocaine) into the brachial artery using the Seldinger technique. Heart rate was determined from the continuous electrocardiogram.

In some experiments, a venous catheter (internal diameter $0.7 \mathrm{~mm}$, length $60 \mathrm{~cm}$ ) was inserted percutaneously into an antecubital vein under local anesthesia and advanced to an intrathoracic vein for measurement of central venous pressure.

Forearm vascular resistance was calculated by dividing mean arterial pressure (diastolic pressure plus one-third of pulse pressure in $\mathrm{mmHg}$ ) by forearm blood flow $\left(\mathrm{ml} \cdot \mathrm{min}^{-1} \cdot 100 \mathrm{ml}^{-1}\right.$ forearm volume) and expressed as resistance units.

Venous pooling was produced by application of negative pressure at $-10 \mathrm{mmHg}$ to the lower body, which was enclosed in an airtight box to the level of the iliac crests. Carotid baroreceptor stimulation was decreased by application of positive pressure to the anterolateral neck using a neck collar as previously described (24). Neck pressure decreases transmural carotid pressure (simulated carotid hypotension) and therefore decreases the deformation of carotid baroreceptors (25).

Changes in mean arterial pressure, heart rate, forearm blood flow, and forearm vascular resistance which resulted from LBNP alone (cardiopulmonary baroreflex) and neck pressure alone (carotid baroreflex) were compared with those that occurred when lower body negative pressure and neck pressure were performed simultaneously (interaction of cardiopulmonary and carotid baroreflexes).

Responses to the cold pressor test were assessed by immersion of the subject's hand in ice water for $2 \mathrm{~min}$. Although the cold pressor test produces reflex forearm vasoconstriction, this response is not triggered by the carotid baroreflex (26).

Responses to the adrenergic neurotransmitter were studied by brachial artery infusion of norepinephrine. Norepinephrine bitartrate was diluted in 5\% dextrose in water and infused into the brachial artery at 37.5 and $75.0 \mathrm{ng} / \mathrm{min}$ sequentially for $4 \mathrm{~min}$ at each dose. Brachial artery infusion of norepinephrine at these concentrations produces dose-dependent decreases in blood flow in the ipsilateral forearm but does not alter systemic arterial pressure, heart rate, or blood flow in the contralateral forearm $(27,28)$. Therefore, this experimental strategy permits assessment of the direct effect of norepinephrine on the resistance vessels in the forearm in the absence of systemic reflex effects. Infusion of vehicle at the maximum infusion rate $(0.6 \mathrm{ml} / \mathrm{min})$ did not alter forearm blood flow.

Protocol. Recordings were made in nine subjects during the following interventions: (a) LBNP at $-10 \mathrm{mmHg}$, (b) neck pressure at $+20 \mathrm{mmHg}$, (c) neck pressure at $+30 \mathrm{mmHg},(d) \mathrm{LBNP}$ at $-10 \mathrm{mmHg}$ plus neck pressure at $+20 \mathrm{mmHg}$, and $(e) \mathrm{LBNP}$ at $-10 \mathrm{mmHg}$ plus neck pressure at $+30 \mathrm{mmHg}$. The order of the five interventions was randomized. Each study period lasted $6 \mathrm{~min}$, including $2 \mathrm{~min}$ each of control, intervention, and recovery. There was a 10 -min rest period between each 6min study period. Forearm blood flow, systemic arterial pressure, heart rate, and forearm vascular resistance determinations were made during the last $60 \mathrm{~s}$ of each 2-min interval.

To test effects of LBNP on vasoconstriction during the cold pressor test, responses were studied in six additional subjects during (a) LBNP at $-10 \mathrm{mmHg},(b)$ cold pressor test, and $(c)$ simultaneous application of LBNP at $-10 \mathrm{mmHg}$ and the cold pressor test.

Additional experiments were conducted in seven more subjects to compare the effect of LBNP on the forearm vascular responses to brachial artery infusion of norepinephrine with the effect of LBNP on the reflex responses to neck pressure. The following interventions were performed: (a) norepinephrine at 37.5 and $75.0 \mathrm{ng} / \mathrm{min},(b)$ norepinephrine at 37.5 and $75.0 \mathrm{ng} / \mathrm{min}$ during LBNP at $-10 \mathrm{mmHg}$, (c) neck pressure at +30 $\mathrm{mmHg}$, and $(d)$ neck pressure at $+30 \mathrm{mmHg}$ during LBNP at -10 $\mathrm{mmHg}$. During the combined interventions, LBNP was always administered first for $90 \mathrm{~s}$, and then the responses to norepinephrine or to neck pressure were superimposed upon the steady-state response to LBNP.

Data analysis. Statistical comparisons were made with the $t$ test for paired observations. Statistical significance was $P<0.05$. Values in the text are mean \pm standard error.

\section{Results}

Effect of $L B N P(-10 \mathrm{mmHg})$. This mild level of LBNP decreased central venous pressure by $3 \pm 1 \mathrm{mmHg}(n=3)$. LBNP produced a small but significant decrease in forearm blood flow but did not cause significant changes in heart rate, mean arterial pressure, or calculated forearm vascular resistance (Table I). Furthermore, LBNP at $-10 \mathrm{mmHg}$ did not alter arterial pulse pressure.

Effect of neck pressure. Table I shows that neck pressure at $+20 \mathrm{mmHg}$ produced a significant elevation in mean arterial pressure but did not significantly increase forearm resistance. Neck pressure at $+30 \mathrm{mmHg}$ increased mean arterial pressure, heart rate, and forearm resistance (Table I). Neck pressure did not alter central venous pressure.

Effect of LBNP on responses to neck pressure. Table I and Figs. 1 and 2 show that LBNP caused a greater than twofold increase in the forearm vasoconstrictor responses to neck pressure at +20 and at $+30 \mathrm{mmHg}$. Most importantly, the increase in forearm resistance during concomitant application of LBNP at $-10 \mathrm{mmHg}$ and neck pressure at $+30 \mathrm{mmHg}$ was significantly greater than the algebraic sum of the increases in forearm resistance during LBNP alone and neck pressure alone (Table I, Figs. 1 and 2).

In contrast, LBNP did not augment the increases in heart rate during neck pressure (Table I, Figs. 1 and 2).

Effect of LBNP on vascular responses to the cold pressor test. LBNP did not augment reflex forearm vasoconstriction during the cold pressor test (Fig. 3). In the 2 nd min of the interventions, the increase in forearm resistance during simultaneous appli- 


\begin{tabular}{|c|c|c|c|c|}
\hline & Heart rate & $\begin{array}{l}\text { Mean arterial } \\
\text { pressure }\end{array}$ & $\begin{array}{l}\text { Forearm blood } \\
\text { flow }\end{array}$ & $\begin{array}{l}\text { Forearm vascular } \\
\text { resistance }\end{array}$ \\
\hline & beats/min & $m m H g$ & $\mathrm{ml} / \mathrm{min}$ per $100 \mathrm{ml}$ & $U$ \\
\hline \multicolumn{5}{|l|}{ Effect of LBNP } \\
\hline Control & $58 \pm 3$ & $84 \pm 2$ & $3.3 \pm 0.3$ & $28.2 \pm 3.6$ \\
\hline LBNP (-10 mmHg) & $56 \pm 3$ & $83 \pm 2$ & $3.0 \pm 0.3^{*}$ & $30.3 \pm 3.6$ \\
\hline Recovery & $59 \pm 3$ & $84 \pm 2$ & $3.3 \pm 0.4$ & $28.9 \pm 4.3$ \\
\hline \multicolumn{5}{|l|}{ Effect of NP } \\
\hline Control & $59 \pm 3$ & $84 \pm 2$ & $3.5 \pm 0.3$ & $25.7 \pm 2.9$ \\
\hline $\mathrm{NP} 20 \mathrm{mmHg}$ & $59 \pm 3$ & $90 \pm 3^{*}$ & $3.4 \pm 0.3$ & $28.0 \pm 2.7$ \\
\hline Recovery & $58 \pm 3$ & $85 \pm 2$ & $3.3 \pm 0.3$ & $27.9 \pm 3.4$ \\
\hline Control & $57 \pm 2$ & $85 \pm 2$ & $3.6 \pm 0.4$ & $26.3 \pm 3.4$ \\
\hline $\mathrm{NP} 30 \mathrm{mmHg}$ & $62 \pm 3^{*}$ & $97 \pm 3^{*}$ & $3.5 \pm 0.4$ & $31.1 \pm 4.2^{*}$ \\
\hline Recovery & $58 \pm 2$ & $84 \pm 2$ & $3.5 \pm 0.4$ & $27.1 \pm 3.6$ \\
\hline \multicolumn{5}{|l|}{ Effect of LBNP plus NP } \\
\hline Control & $57 \pm 2$ & $87 \pm 2$ & $3.5 \pm 0.4$ & $26.4 \pm 3.0$ \\
\hline $\mathrm{LBNP}+20 \mathrm{~mm} \mathrm{NP}$ & $58 \pm 3$ & $89 \pm 2$ & $3.0 \pm 0.3^{*}$ & $32.7 \pm 3.6^{*}$ \\
\hline Recovery & $57 \pm 3$ & $85 \pm 1$ & $3.3 \pm 0.3$ & $27.7 \pm 3.1$ \\
\hline Control & $58 \pm 2$ & $86 \pm 2$ & $3.6 \pm 0.3$ & $25.4 \pm 2.7$ \\
\hline $\mathrm{LBNP}+30 \mathrm{~mm} \mathrm{NP}$ & $61 \pm 3$ & $97 \pm 2^{*}$ & $2.9 \pm 0.3 \ddagger$ & $38.2 \pm 5.3 \ddagger$ \\
\hline Recovery & $57 \pm 2$ & $86 \pm 2$ & $3.8 \pm 0.3$ & $28.2 \pm 3.2$ \\
\hline
\end{tabular}

Entries represent the mean value \pm standard error for nine subjects. Abbreviations: LBNP, lower body negative pressure; NP, neck pressure. * Values that are significantly different from control $(P<0.05)$. $¥$ The response to LBNP plus NP is significantly greater $(P<0.05)$ than the algebraic sum of the response to LBNP alone plus that to NP alone.

cation of LBNP and the cold pressor test $(+8.4 \pm 1.7 \mathrm{U})$ was actually significantly less $(P<0.05)$ than the algebraic sum of the increases during LBNP alone $(+2.1 \pm 0.4 \mathrm{U})$ and the cold pressor test alone $(+11.3 \pm 2.9 \mathrm{U})$. Furthermore, the pressor response during the 2 nd min of the combined intervention $(+16 \pm 3$ $\mathrm{mmHg})$ was also significantly less $(P<0.05)$ than the sum of the responses to LBNP alone $(-1 \pm 1 \mathrm{mmHg})$ and to the cold pressor test alone $(20 \pm 3 \mathrm{mmHg})$.

Effect of LBNP on vasoconstrictor responses to norepinephrine. Fig. $4 \mathrm{~A}$ shows that brachial artery infusion of norepinephrine produced dose-dependent increases in forearm resistance and that the slope of this dose-response relationship was not altered by LBNP.

In contrast, in the same experiments LBNP augmented the reflex forearm vasoconstrictor response to neck pressure at 30 $\mathrm{mmHg}$ (Fig. 4 B). Neck pressure alone produced only a small but significant increase in forearm vascular resistance from $18.3 \pm 3.0$ to $20.5 \pm 3.7 \mathrm{U}(P<0.05$ vs. control); however, when neck pressure was applied during LBNP, forearm vascular resistance increased more sharply from $20.5 \pm 3.1$ to $25.4 \pm 4.4 \mathrm{U}$ $(P<0.05$ responses to neck pressure alone versus neck pressure responses during $L B N P$ ).

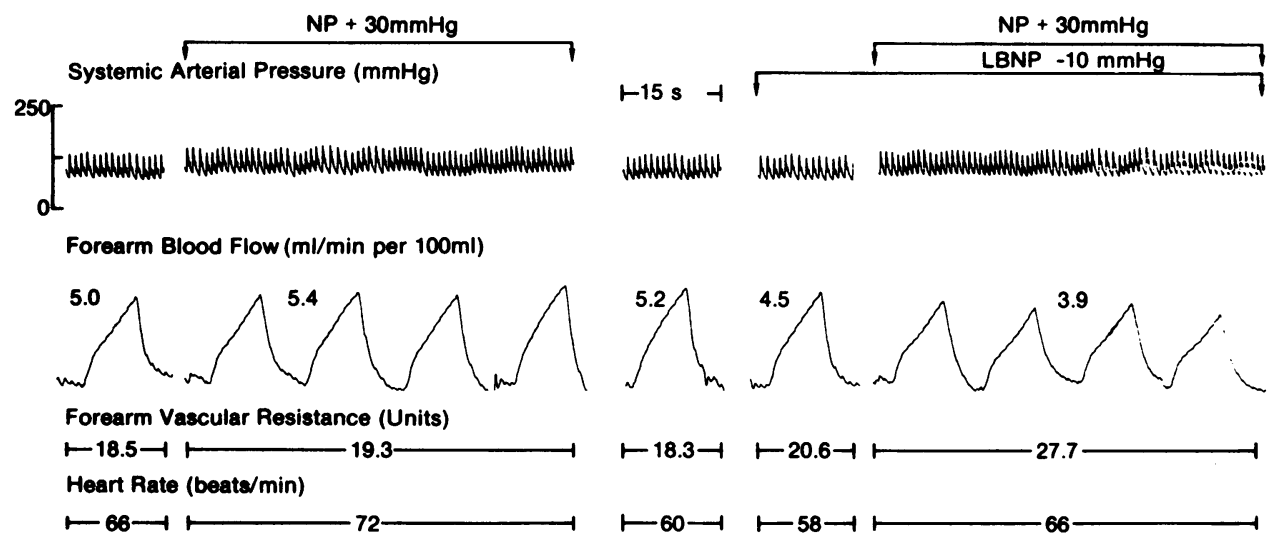

Figure 1. Direct recording of systemic arterial pressure and plethysmographic measurements of forearm blood flow in one subject during neck pressure (NP) alone, during lower body negative pressure (LBNP) alone, and during concomitant application of neck pressure and LBNP. Values for forearm blood flow are averages of the last four determinations during each measurement period. Corresponding values of forearm vascular resistance and heart rate are also shown. This figure shows that the vasoconstrictor response to neck pressure was markedly augmented during LBNP. 


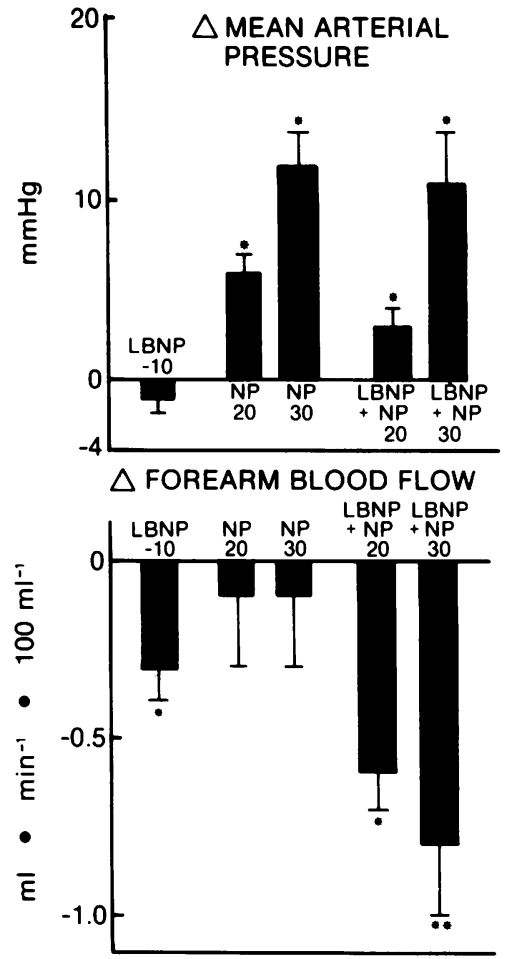

\section{Discussion}

These experiments demonstrate an inhibitory interaction between cardiopulmonary and carotid baroreflex control of vascular resistance in humans. Unloading of cardiopulmonary receptors with nonhypotensive LBNP selectively augmented reflex forearm vasoconstrictor responses to simulated carotid hypotension produced by neck pressure. This augmentation was significantly greater than the simple algebraic sum of the vasoconstriction caused by LBNP alone plus that caused by neck pressure alone. In addition, the slope of the response to neck pressure at 20 and $30 \mathrm{mmHg}$ became steeper (Fig. 2). A steeper stimulus-

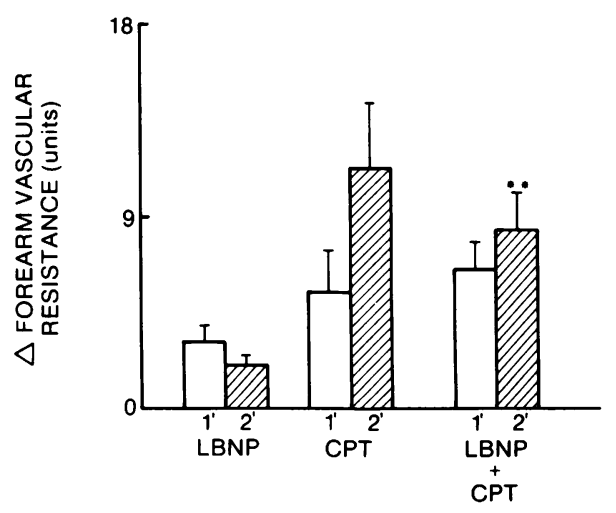

Figure 3. Changes in forearm vascular resistance during $2 \mathrm{~min}$ of LBNP at $-10 \mathrm{mmHg}$, of the cold pressor test (CPT) alone, and of concomitant administration of LBNP and the cold pressor test. Double asterisk (**) indicates that the response to LBNP plus the cold pressor test is significantly less $(P<0.05)$ than the sum of the response to the cold pressor test alone plus that to LBNP alone. Values are mean \pm standard error for six subjects.
Figure 2. Changes in heart rate, mean arterial pressure, forearm blood flow, and forearm vascular resistance that resulted from lower body negative pressure (LBNP) at -10 $\mathrm{mmHg}$, from neck pressure (NP) at 20 and $30 \mathrm{mmHg}$, and from concomitant LBNP and neck pressure at 20 and $30 \mathrm{mmHg}$. The changes in each subject were calculated by subtracting the value obtained during the intervention from the control value. Asterisk (*) indicates a significant change $(P<0.05$ vs. control). Double asterisk (**) indicates that the response to LBNP plus neck pressure is significantly greater $(P<0.05)$ than the algebraic sum of the response to LBNP alone plus that to neck pressure alone. Values are mean \pm standard error for nine subjects. response curve and a net response greater than the sum of the two individual responses strongly supports the presence of an inhibitory interaction between cardiopulmonary and carotid baroreflexes.

The discussion focuses on four questions. (a) Could the augmented responses to neck pressure during LBNP be explained by a nonspecific excitatory influence of altered baseline vasomotor tone or of LBNP itself on vascular reactivity to norepinephrine? (b) Could the augmented responses to neck pressure during LBNP be explained by a nonspecific effect of LBNP on the relationship between sympathetic nerve activity and the release of adrenergic neurotransmitter from peripheral adrenergic nerve terminals? (c) Can we exclude a direct effect of LBNP on carotid baroreceptor discharge in the interpretation of the forearm vascular responses? $(d)$ What is the evidence that these findings indicate a central inhibitory interaction of baroreceptor afferents?

Base-line values of forearm resistance prior to concomitant application of neck pressure plus LBNP were equivalent to those in the control period prior to application of neck pressure alone (Table I). Thus, altered base-line vasomotor tone cannot explain the augmented vasoconstriction during simultaneous application of LBNP and neck pressure at $30 \mathrm{mmHg}$. In the subsequent series of experiments, however, LBNP was applied before the onset of neck pressure. Therefore, LBNP might have altered the vascular responses to neck pressure at $30 \mathrm{mmHg}$ by elevating the initial value of forearm vascular resistance upon which the neck pressure response was superimposed $(29,30)$. The intraarterial infusion of norepinephrine provides an internal control for this possibility. Whereas LBNP produced augmented reflex vasoconstrictor responses to neck pressure in these subjects (Fig. $4 B$ ), vasoconstrictor responses to norepinephrine were not potentiated by LBNP (Fig. $4 A$ ). Therefore, increased base-line vasomotor tone does not produce a nonselective, generalized 


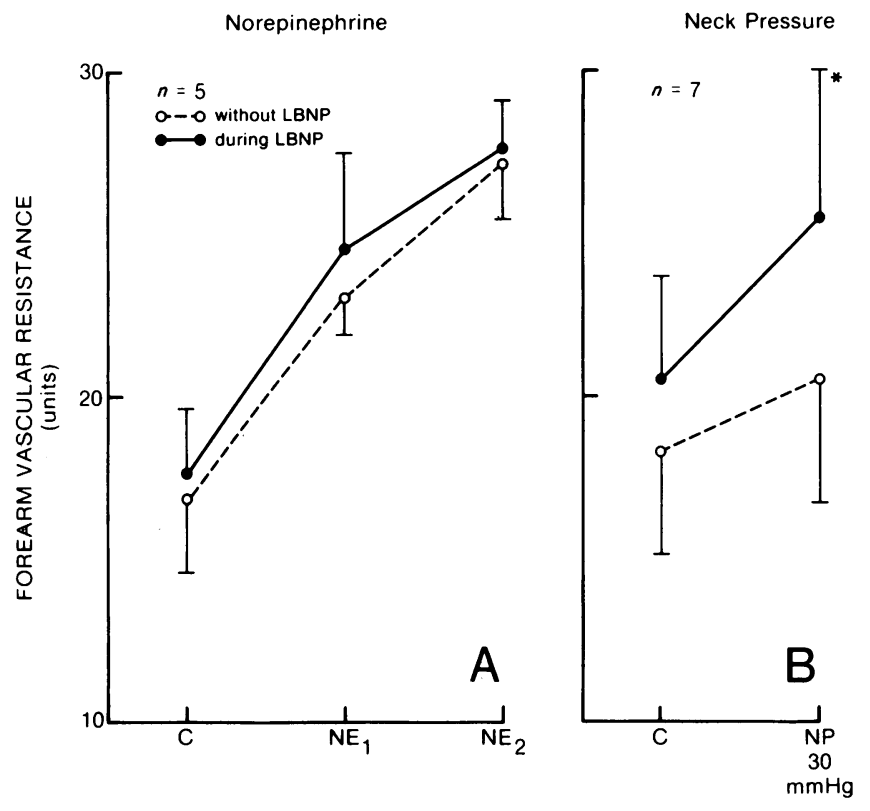

Figure 4. Comparison of effects of LBNP on forearm vascular responses to intra-arterial norepinephrine $(A)$ and to neck pressure $(B) .(A)$ Forearm vascular resistance during control $(C)$ and during brachial artery infusion of norepinephrine at $37.5\left(\mathrm{NE}_{1}\right)$ and $75.0\left(\mathrm{NE}_{2}\right) \mathrm{ng} / \mathrm{min}$. Norepinephrine was infused $(a)$ under base-line conditions (without LBNP), and (b) during LBNP at $-10 \mathrm{mmHg}$. Intra-arterial norepinephrine produced dose-dependent increases in forearm vascular resistance. The slope of the dose-response curve was unchanged during LBNP. Data are mean \pm standard error for five subjects. $(B)$ Forearm vascular resistance during control (C) and during neck pressure (NP) at $30 \mathrm{mmHg}$. Neck pressure was administered $(a)$ under base-line conditions (without LBNP), and (b) during LBNP at $-10 \mathrm{mmHg}$. Asterisk $(*)$ indicates that the increase in forearm vascular resistance produced by neck pressure was significantly greater $(P<0.05)$ during LBNP. Data are mean \pm standard error for seven subjects.

enhancement of superimposed vasoconstrictor responses in this setting.

The norepinephrine responses also demonstrate that the effect of LBNP on the neck pressure responses cannot be explained by a generalized facilitation of vascular responsiveness to the adrenergic neurotransmitter during LBNP. These findings alone, however, do not prove that the mechanism of enhanced forearm vascular responses to neck pressure during LBNP is increased central activation of sympathetic vasoconstrictor nerves for two reasons. First, the relationship between the degree of activation of the sympathetic nerves and the output of norepinephrine from the peripheral adrenergic nerve endings is not necessarily linear $(31,32)$. Thus, the finding of an augmented vasoconstrictor response to concomitant application of two vasoconstrictor stimuli, namely neck pressure and LBNP, could be due to a nonlinear relationship between sympathetic nerve activity and neurotransmitter release. Second, LBNP might stimulate adrenomedullary secretion of epinephrine, which in turn could facilitate release of norepinephrine from adrenergic varicosities by stimulation of prejunctional $\beta$-adrenoreceptors (33-35).

If LBNP alters the relationship between sympathetic nerve activity and norepinephrine release by either of these two mechanisms, one would predict that LBNP should also cause augmented forearm vascular responses to any stimulus that produces reflex increases in sympathetic neural drive. To test this possi- bility, we examined the effect of LBNP on reflex forearm vasoconstrictor responses to the cold pressor test in that preliminary microneurographic experiments in this laboratory indicate that a major component of the vasoconstrictor response to the cold pressor test is central activation of muscle sympathetic nerve activity (36). There was no augmentation of the forearm vascular responses to the cold pressor test during LBNP. In fact, these responses were significantly attenuated by concomitant application of LBNP (Fig. 3). The findings are consistent with animal experiments which indicate that increasing levels of peripheral sympathetic nerve stimulation cause progressively smaller vasoconstrictor responses (31). Thus, the augmented responses to neck pressure during LBNP occur in spite of, and not because of, the effect of LBNP on the relationship between sympathetic nerve activity and norepinephrine secretion during concomitant application of vasoconstrictor stimuli. Regardless of the precise neurophysiologic mechanism that underlies these observations, the cold pressor responses demonstrate that LBNP does not engender a generalized, nonselective enhancement of forearm vascular responses to superimposed reflex vasoconstrictor stimuli.

Taken together, these experiments document that LBNP produces selective augmentation of reflex forearm vasoconstriction during concomitant application of neck pressure. The findings provide strong evidence of a central, inhibitory interaction of cardiopulmonary and carotid baroreflexes.

This interpretation of the forearm vascular responses assumes that LBNP at $-10 \mathrm{mmHg}$ produces selective unloading of cardiopulmonary vagal afferents. Therefore, we should consider the possibility that even this low level of nonhypotensive LBNP might alter afferent discharge in the carotid sinus nerve. For example, augmented vasoconstriction during concomitant LBNP and neck pressure might be explained either by a direct influence of LBNP on the mechanical determinants of carotid baroreceptor activity or by an interactive effect that occurs at the level of the carotid baroreceptors (afferent interaction) rather than within the central nervous system (central interaction).

Arterial baroreceptor discharge is mechanically determined by the relationship between arterial distending pressure and vessel diameter, or wall strain (37). LBNP at $-10 \mathrm{mmHg}$ did not affect carotid distending pressure inasmuch as arterial systolic, diastolic, mean, and pulse pressure were unchanged during administration of LBNP alone. Even though we could not measure carotid sinus diameter in our human subjects, we can infer that LBNP at -10 $\mathrm{mmHg}$ did not significantly alter carotid wall strain because this level of LBNP alone did not trigger reflex changes in heart rate. Thus, nonhypotensive LBNP per se does not produce a major perturbation in the carotid baroreflex.

Nevertheless, even subtle stimulation of the carotid sinus baroreceptors during LBNP could influence the response to concomitant application of neck pressure. Recent animal experiments indicate that norepinephrine can increase arterial baroreceptor activity, presumably by a direct action on the baroreceptor ending (38). In addition, electrical stimulation of the cervical sympathetic nerves and direct application of norepinephrine to the carotid sinus have produced significant increases in carotid sinus nerve firing $(39,40)$. Furthermore, Felder et al. (41) have recently demonstrated that stimuli that produce reflex sympathetic excitation, such as vena caval ligation or carotid artery occlusion, can trigger increases in baroreceptor discharge in the vascularly isolated contralateral carotid sinus. Because even low levels of LBNP have been shown to produce sustained increases in efferent sympathetic nerve activity (42), LBNP at 
$-10 \mathrm{mmHg}$ might increase carotid baroreceptor activity through reflex augmentation of sympathetic neural drive.

In other words, one could argue that LBNP at $-10 \mathrm{mmHg}$ decreases cardiopulmonary baroreceptor discharge but increases carotid baroreceptor discharge by reflex sympathetic stimulation. Because increased carotid baroreceptor activity promotes vasodilatation, enhanced vasoconstriction during simultaneous LBNP and neck pressure (the latter decreases carotid baroreceptor activity) would have occurred in spite of, rather than because of, an excitatory effect of LBNP on the carotid baroreceptors.

More importantly, comparison of the heart rate and the vasoconstrictor responses to the combined intervention (neck pressure plus LBNP) provides the experimental evidence that LBNP does not stimulate the carotid baroreceptors in this setting. If LBNP had altered carotid baroreceptor discharge, then LBNP should have potentiated the heart rate responses as well as the vasoconstrictor responses during concomitant application of neck pressure. Although LBNP more than doubled the forearm vasoconstrictor responses to neck pressure at $30 \mathrm{mmHg}$, the increases in heart rate during neck pressure were not augmented by LBNP (Table I and Figs. 1 and 2). These observations are consistent with data from previous human experiments in which physiologic changes in central nervous pressure did not affect carotid baroreflex control of heart rate (13). This specificity of the cardiopulmonary-carotid baroreflex interaction in humans for the control of vascular resistance rather than heart rate strengthens the conclusion that the interactive effect occurs within the central nervous system and not at the level of the carotid baroreceptors.

In conclusion, these experiments provide the first clear evidence in humans for an inhibitory interaction between cardiopulmonary and carotid baroreflexes. The findings provide a potential explanation for previous observations in supine human subjects that carotid baroreflex perturbations produce only very transient effects on muscle sympathetic nerve activity and forearm vascular resistance (42-44). In our experiments, neck pressure produced an augmented and sustained vasoconstrictor response during simulated orthostatic stress with LBNP. These findings indicate that cardiac vagal afferents exert a profound inhibitory influence on the carotid baroreflex under supine conditions and suggest that carotid baroreceptors may be quite important in triggering reflex vasoconstriction when this inhibitory influence is removed during upright posture.

The findings in normal subjects also suggest important mechanistic implications regarding the reflex vascular adjustments that take place in pathophysiologic states in patients. During systemic hypotension, arterial baroreceptors should trigger sympathetic neural excitation and peripheral vasoconstriction. Based on our findings in healthy human subjects and those from studies in experimental animals (3-12), we speculate that these compensatory neurocirculatory adjustments would be modified greatly by concomitant alterations in cardiopulmonary vagal afferent discharge. In hemorrhagic shock, for example, patients are hypotensive as well as hypovolemic so that both carotid and cardiopulmonary baroreceptors are unloaded simultaneously. In this respect, hypovolemic hypotension is analogous to the experimental condition of neck pressure applied during LBNP. Therefore, in hemorrhagic shock, decreased cardiopulmonary receptor discharge should potentiate the arterial baroreflex and lead to augmented vasoconstriction in the extremities.
In contrast, when hypotension accompanies acute myocardial infarction, increased stimulation of cardiac vagal afferents may inhibit the arterial baroreflex (45-53). Impaired vasoconstriction during cardiogenic shock could provide an important mechanism for preventing deleterious elevations in left ventricular afterload.

\section{Acknowledgments}

The authors thank Dr. Herman Falsetti for his advice and input into the preliminary experiments and Dr. Donald Heistad for this thoughtful review. We also thank Sara Jedlicka for secretarial assistance.

This work was supported by research grants HL24962 and HL14388 and by a National Research Service Award to Dr. Victor all from the National Heart, Lung, and Blood Institute and by research funds from the Veterans Administration.

\section{References}

1. Victor, R. G., H. L. Falsetti, J. Tracy, and A. L. Mark. 1983. Interaction of cardiopulmonary and carotid baroreceptor reflexes in humans. Circulation. 68:III-248. (Abstr.)

2. Abboud, F. M., and M. D. Thames. 1983. Interaction of cardiovascular reflexes in circulatory control. Handb. Physiol. (Sect. 2. Cardiovasc. Syst.) 3(Pt. 2):675-754.

3. Vatner, S. F., D. H. Boettcher, G. H. Hendrickx, and R. J. McRitchie. 1975. Reduced baroreflex sensitivity with volume loading in conscious dogs. Círc. Res. 37:236-242.

4. Billman, G. E., D. T. Dickey, K. K. Teoh, and H. L. Stone. 1981. Effects of central venous blood volume shifts on arterial baroreflex control of heart rate. Am. J. Physiol., 241:H571-H575.

5. Thorén, P. 1979. Role of cardiac vagal C-fibers in cardiovascular control. Rev. Physiol. Biochem. Pharmacol. 86:1-94.

6. Pillsbury, H. R. C. III, M. Guazzi, and E. D. Fries. 1969. Vagal afferent depressor nerves in the rabbit. Am. J. Physiol. 217:768-770.

7. Guazzi, M., A. Libretti, and A. Zanchetti. 1962. Tonic reflex regulation of the cat's blood pressure through vagal afferents from the cardiopulmonary region. Circ. Res. 11:7-16.

8. Öberg, B., and S. White. 1970. Circulatory effects of interruption and stimulation of cardiac vagal afferents. Acta. Physiol. Scand. 80:383394.

9. Mancia, G., D. E. Donald, and J. T. Shepherd. 1973. Inhibition of adrenergic outflow to peripheral blood vessels by vagal afferents from the cardiopulmonary region in the dog. Circ. Res. 33:713-721.

10. Mancia, G., J. T. Shepherd, and D. D. Donald. 1976. Interplay among carotid sinus, cardiopulmonary and carotid body reflexes in dogs. Am. J. Physiol. 230:19-24.

11. Donald, D. E., and J. T. Shepherd. 1978. Reflexes from the heart and lungs: physiological curiosities or important regulatory mechanisms. Cardiovasc. Res. 12:449-469.

12. Koike, H., A. L. Mark, D. D. Heistad, and P. G. Schmid. 1975. Influence of cardiopulmonary vagal afferent activity on carotid chemoreceptor and baroreceptor reflexes in the dog. Circ. Res. 37:422-429.

13. Takeshita, A., A. L. Mark, D. L. Eckberg, and F. M. Abboud. 1979. Effect of central venous pressure on arterial baroreflex control of heart rate. Am. J. Physiol. 236:H42-H47.

14. Bevegård, S., J. Castenfors, L. E. Lindblad, and J. Tranesjo. 1977. Blood pressure and heart rate regulating capacity of the carotid sinus during changes in blood volume distribution in man. Acta. Physiol. Scand. 99:300-312.

15. Bevegård, S., J. Castenfors, and L. E. Lindblad. 1977. Effect of carotid sinus stimulation on cardiac output and peripheral vascular resistance during changes in blood volume distribution in man. Acta. Physiol. Scand. 101:50-57.

16. Abboud, F. M., D. L. Eckberg, U. J. Johannsen, and A. L. Mark. 1979. Carotid and cardiopulmonary baroreceptor control of splanchnic and forearm vascular resistance during venous pooling in man. J. Physiol. (Lond.). 286:173-184. 
17. Abboud, F. M., A. L. Mark, D. D. Heistad, D. L. Eckberg, and P. G. Schmid. 1975. Selectivity of autonomic control of the peripheral circulation in man. Trans. Am. Clin. Climatol. Assoc. 184-197.

18. Wallin, G. 1983. Intraneural recording and autonomic function in man. In Autonomic Failure. R. Bannister, editor. Oxford University Press, London. 36-51.

19. Roddie, I. C., J. T. Shepherd, and R. F. Whelan. 1957. Reflex changes in vasoconstrictor time in human skeletal muscle in response to stimulation of receptors in a low-pressure area of the intrathoracic vascular bed. J. Physiol. (Lond.). 139:369-376.

20. Zoller, R. P., A. L. Mark, F. M. Abboud, P. G. Schmid, and D. D. Heistad. 1972. The role of low pressure baroreceptors in reflex forearm vasoconstrictor responses in man. J. Clin. Invest. 51:2967-2972.

21. Johnson, J. M., L. B. Powell, M. Neederberger, and M. M. Eisman. 1974. Human splanchnic and forearm vasoconstrictor responses to reductions of right atrial and aortic pressures. Circ. Res. 34:515-524.

22. Wolthuis, R. A., S. A. Bergman, and A. E. Nicogossian. 1974. Physiological effects of locally applied reduced pressure in man. Physiol. Rev. 54:566-595.

23. Greenfield, A. D. M., R. J. Whitney, and J. Mowbray. 1963. Methods for the investigation of peripheral blood flow. Br. Med. Bull. 19:101-109.

24. Ferguson, D. W., M. D. Thames, and A. L. Mark. 1983. Effects of propranolol on reflex vascular responses to orthostatic stress in humans: role of ventricular baroreceptors. Circulation. 67:802-807.

25. Ludbrook, J., G. Mancio, A. Ferrari, and A. Zanchetti. 1977. The variable-pressure neck-chamber method for studying the carotid baroreflex in man. Clin. Sci. Mol. Med. 53:165-171.

26. Nies, A. S. 1978. Cardiovascular disorders: hypertension. In Clinical Pharmacology. K. L. Melmon and H. F. Morrell, editors. Macmillan Publishing Co., Inc., New York. 155-209.

27. Roddie, I. C., and W. F. M. Wallace. 1979. Methods for the assessment of the effects of drugs on the arterial system in man. $B r . J$. Clin. Pharmacol. 7:317-323.

28. Mark, A. L., W. J. Lawton, F. M. Abboud, A. E. Fitz, W. E. Connor, and D. D. Heistad. 1975. Effects of high and low sodium intake on arterial pressure and forearm vascular resistance in borderline hypertension. Circ. Res. 36:1194-1198.

29. Wilder, P. 1967. The Law of Initial Values. Wright and Sons, Ltd., The Stonebridge Press, Bristol, England. 1-141.

30. Meyers, H. A., and C. R. Honig. 1969. Influence of initial resistance on the magnitude of response to vasomotor stimuli. Am. J. Physiol. 216:1429-1436.

31. Heistad, D. D., F. M. Abboud, A. L. Mark, and P. G. Schmid. 1974. Interaction of baroreceptor and chemoreceptor reflexes: modulation of the chemoreceptor reflex by changes in baroreceptor activity. J. Clin. Invest. 53:1226-1236.

32. Vanhouette, P. M., T. J. Verbeuren, and R. C. Webb. 1981. Local modulation of adrenergic neuroeffector interaction on the blood vessel wall. Physiol. Rev. 61:151-247.

33. Berecek, K. H., and M. J. Brody. 1982. Evidence for a neurotransmitter role for epinephrine derived from the adrenal medulla. Am. J. Physiol. 242:H593-H601.

34. Langer, S. Z. 1981. Presynaptic regulation of the release of catecholamines. Pharmacol. Rev. 32:337-362.

35. Stjorne, L., and J. Brunden. 1976. Beta-2-adrenoreceptor facil- itating noradrenaline secretion from human vasoconstrictor nerves. Acta. Physiol. Scand. 97:88-93.

36. Victor, R. G., W. N. Leimbach, Jr., B. G. Wallin, and A. L. Mark. 1985. Microneurographic evidence for increased central sympathetic neural drive during the cold pressor test. J. Am. Coll. Cardiol. 5: 415. (Abstr.)

37. Brown, A. M. 1980. Receptors under pressure: an update on baroreceptors. Circ. Res. 46:1-10.

38. Goldman, W. F., and W. R. Saum. 1984. A direct excitatory action of catecholamines on rat aortic baroreceptors in vitro. Circ. Res. 55:18-30.

39. Bolter, C. P., and J. R. Ledseme. 1976. Effect of cervical sympathetic nerve stimulation on canine carotid sinus reflex. Am. J. Physiol. 230:1026-1030.

40. Tomomatsu, E., and K. Nishi. 1981. Increased activity of carotid sinus baroreceptors by sympathetic stimulation and norepinephrine. $\mathrm{Am}$. J. Physiol. 240:H650-H658.

41. Felder, R. B., C. M. Heesch, and M. D. Thames. 1983. Reflex modulation of carotid sinus baroreceptor activity in the dog. Am. J. Physiol. 244:H437-H443.

42. Sundlöf, G., and B. G. Wallin. 1978. Effect of lower body negative pressure on human muscle nerve sympathetic activity. J. Physiol. (Lond.). 278:525-532.

43. Bath, E., L. E. Lindblad, and B. G. Wallin. 1981. Effects of dynamic and static neck suction on muscle sympathetic nerve activity, heart rate, and blood pressure in man. J. Physiol. (Lond.). 311:551-564.

44. Lindblad, L. E., B. G. Wallin, and S. Bevegård. 1982. Transient vasodilatation in the forearm on stimulation of carotid baroreceptors in man. J. Auton. Nerv. Syst. 5:373-379.

45. Wallin, B. G., and D. L. Eckberg. 1982. Sympathetic transients caused by abrupt alterations of carotid baroreceptor activity in humans. Am. J. Physiol. 242:H185-H190.

46. Toubes, D. B., and M. J. Brody. 1970. Inhibition of reflex vasoconstriction after experimental coronary embolization in the dog. Circ. Res. 26:211-224.

47. Hanley, H. G., A. E. Raizner, T. V. Inglesby, and N. S. Skinner, Jr. 1972. Response of the renal vascular bed to acute experimental coronary arterial occlüsion. Am. J. Cardiol. 29:803-808.

48. Thorén, P. 1973. Evidence for a depressor reflex elicited from left ventricular receptors during occlusion of one coronary artery in the cat. Acta. Physiol. Scand. 88:23-34.

49. Maximov, M. J., and M. J. Brody. 1976. Changes in regional vascular resistance after myocardial infarction in the dog. Am. J. Cardiol. 37:26-31.

50. Gorfinkel, H. J., J. P. Szidon, L. J. Hirsch, and A. P. Fishman. 1972. Renal performance in experimental cardiogenic shock. Am. J. Physiol. 222:1260-1268.

51. Kezdi, P., R. K. Kordenat, and S. N. Misra. 1974. Reflex inhibitory effects of vagal afferents in experimental myocardial infarction. Am. J. Cardiol. 33:853-860.

52. Thames, M. D., and F. M. Abboud. 1979. Reflex inhibition of renal sympathetic nerve activity during myocardial ischemia mediated by left ventricular receptors with vagal afferents in dogs. J. Clin. Invest. 63:395-402.

53. Waickman, L. A., and F. M. Abboud. 1980. Circumflex coronary occlusion inhibits the compensatory increase in sympathetic activity during arterial hypotension. Clin. Res. 28:717A. (Abstr.) 